\title{
Perfil Fosfolipídico Pulmonar em Recém-nascidos de Ratas Diabéticas
}

\author{
Lung Phospholipid Profile in the Pups of Diabetic Rats \\ Marilza Vieira Cunha Rudge, Iracema de Mattos Paranhos Calderon, Maria Delgi Ramos \\ Ana Carolina Japur de Sá, Paulo Roberto Curi
}

\begin{abstract}
RESUMO
Objetivo: avaliar as repercussões do diabete materno sobre o perfil fosfolipidico pulmonar de fetos de ratas com diabete moderado e grave pelas dosagens de lecitina (L), esfingomielina (E), fosfatidil-glicerol (PG), fosfatidil-inositol (PI) e relações L/E e PG/PI.

Métodos: foram utilizadas 54 ratas Wistar, em idade reprodutiva, introduzidas na seqüência experimental de diabete e prenhez ${ }^{1}$. O diabete foi induzido por aloxana $142 \mathrm{mg} / \mathrm{kg}$ de peso, IV) e compostos três grupos: controle, diabete moderado (DM, glicemia entre 120 e $200 \mathrm{mg} /$ $d L$ ) e diabete grave ( $D G$, niveis superiores a $200 \mathrm{mg} / \mathrm{dL}$ ). Realizou-se cesárea no $21^{\circ}$ dia, os pulmões fetais foram macerados, reunidos em "pool" e os fosfolipídios dosados por cromatografia em camada delgada unidirecional.

Resultados: os pulmões dos filhotes das ratas com diabete moderado tiveram maior peso $(0,159$ g) e menor concentração de $P G(3,0 \mu \mathrm{g} / \mathrm{mL})$ e $P I(3,4 \mu \mathrm{g} / \mathrm{mL})$ que o grupo controle $(0,155 \mathrm{~g} ; 6,8$ e $6,7 \mu \mathrm{g} / \mathrm{mL})$, e as mesmas relações $L / E(2,2)$ e PG/PI $(2,0)$; os pulmões dos filhotes das ratas com diabete grave tiveram menor peso $(0,145 \mathrm{~g})$, os mesmos valores das relações $L / E(1,9) e$ PG/PI $(2,1)$ e menor valor de PI $(5,1 \mu \mathrm{g} / \mathrm{mL})$ que o grupo controle.

Conclusões: 1) o retardo do amadurecimento pulmonar dos recém-nascidos de ratas com diabete moderado é explicado pelo maior peso pulmonar associado à menor concentração de PG e PI; 2) a aceleração do amadurecimento pulmonar dos recém-nascidos de ratas com diabete grave é explicada pelo menor peso pulmonar associado à mesma concentração de PG e PI.
\end{abstract}

PALAVRAS-CHAVE: Diabete. Maturidade pulmonar. Perfil fosfolipidico pulmonar.

\section{Introdução}

O diabete materno altera a sintese e a secreção dos fosfolipídios pulmonares. Vários trabalhos mostram atraso na maturação bioquímica do pulmão fetal de gestantes diabéticas ${ }^{2,3}$, fator responsável pela maior incidência de sindrome do desconforto respiratório (SDR) nesses recémnascidos ${ }^{4}$. Entretanto, permanece sem explicação o fato de que uma patologia, que se caracteriza por hiperglicemia materna, possa atrasar a maturidade pulmonar nas diabéticas gestacionais e nas clínicas de curta duração, e acelerá-la nas diabéticas clínicas com vasculopatia ${ }^{2-6}$. Alguns especulam sobre a influência dos quadros hipertensi-

Laboratório Experimental de Obstetrícia - Departamento de Ginecologia e Obstetrícia da Faculdade de Medicina de Botucatu - UNESP

Correspondência:

Marilza Vieira Cunha Rudge

Rua General Telles, 1396 - ap.81

18602-120 - Botucatu - SP

Trabalho financiado pela FAPESP vos e da vasculopatia como fatores aceleradores da maturidade pulmonar fetal nessas gestantes diabéticas.

O perfil fosfolipídico pulmonar, que consiste na determinação da relação lecitina/esfingomielina (L/E) e de fosfatidil-inositol (PI) e fosfatidilglicerol (PG) no líquido amniótico, aumenta a acurácia do diagnóstico de maturidade pulmonar em diabéticas ${ }^{7}$. O surfactante maduro, isto é, o que contém $\mathrm{PG}$, tem melhor propriedade estabilizadora do alvéolo ${ }^{8}$, sendo a sua determinação o método preditivo acurado da maturidade pulmonar fetal.

Vários trabalhos experimentais in vivo e in vitro foram feitos para analisar o efeito do diabete sobre a maturidade pulmonar fetal ${ }^{6}$, sendo que os in vivo trazem respostas mais adequadas. Os filhotes de macacas rhesus diabéticas têm menor habilidade em sintetizar, estocar e liberar a lecitina ${ }^{9}$ e os de coelhas diabéticas, menor quantidade de surfactante no lavado pulmonar ${ }^{10}$. O pulmão dos fetos de ratas diabéticas tem imatu- 
ridade morfológica no pulmão e atraso na produção do surfactante e da regulação do metabolismo de glicogênio fetal ${ }^{3}$. Recém-nascidos de ratas diabéticas apresentam tecido pulmonar imaturo, com células mesenquimais abundantes e espessamento do tecido conectivo pulmonar, o que pode contribuir para o aumento do risco de doença respiratória nestes recém-nascidos ${ }^{11}$. O uso de modelos experimentais em ratas, com niveis glicêmicos variáveis, deve explicar essas diferenças na maturidade pulmonar em filhos de mães diabéticas.

O objetivo geral deste trabalho foi avaliar as repercussões do diabete materno sobre o perfil fosfolipídico pulmonar de fetos de ratas diabéticas, procurando explicar os desvios da maturidade pulmonar fetal. O objetivo específico foi a dosagem de L, E, relação L/E, PG, PI e relação PG/PI nos pulmões de filhotes de ratas com diabete moderado e grave ${ }^{1}$.

\section{Material e Métodos}

\section{Material}

Foram utilizadas 54 ratas da raça Wistar, fêmeas, virgens, em idade reprodutiva de três meses, pesando entre 180 e $250 \mathrm{~g}$. Os animais foram introduzidos na seqüência experimental do modelo de diabete e prenhez, proposto por Calderon et al. ${ }^{1}$, e sorteados para comporem os grupos controle e diabéticos.

A droga diabetogênica foi a aloxana, na dose de $42 \mathrm{mg} / \mathrm{kg}$ de peso IV. A glicemia do $15^{\circ}$ dia do período diabetogênico classificou as ratas como diabéticas moderadas (DM), com glicemia entre 120 e $200 \mathrm{mg} / \mathrm{dL}$, e graves (DG) - (glicemia $>200 \mathrm{mg} / \mathrm{dL})^{1}$.

A prenhez foi resolvida por cesárea, sob anestesia inalatória com éter, na manhã do $21^{\circ}$ dia, quando foram estudados os seguintes parâmetros nos recém-nascidos: glicemia do "pool" da ninhada, peso corpóreo, peso pulmonar e classificação do peso dos filhotes em PIG (pequeno para a idade gestacional), AIP (adequado para a idade gestacional) e GIG (grande para a idade gestacional), a partir da média de peso do grupo controle mais ou menos um desvio padrão ${ }^{1}$. Após a pesagem individual, os pulmões dos recém-nascidos foram reunidos num "pool" representativo de cada ninhada e, no macerado desses pulmões foram dosados os seguintes fosfolipídios: L, E, PG e PI. Foram calculadas as relações L/E e PG/PI. As mães foram sacrificadas por esgotamento da volemia, imediatamente após a retirada dos filhotes.

\section{Métodos}

A glicemia materna do "pool" dos recém-nascidos foi determinada por método enzimático (KitCelm-Barueri-SP). A dosagem dos fosfolipídios foi feita por cromatografia em camada delgada, seguindo o método de Gluck e Kulovich ${ }^{12}$ para líquido amniótico. Foram pesados $200 \mathrm{mg}$ de tecido pulmonar, previamente macerado em gral de porcelana, sob nitrogênio líquido; a seguir, foram homogenizados com $6 \mathrm{ml}$ de mistura clorofórmio:metanol $(2: 1)$.

O macerado foi deixado em repouso por 12 horas e filtrado em papel. Transferiram-se 5 $\mathrm{mL}$ do filtrado para tubo de centrífuga e foram adicionados $1,5 \mathrm{~mL}$ de água deionizada; foram agitados e centrifugados por 20 minutos a 2000 rpm; foi desprezada a fase superior e lavada a fase inferior por três vezes, com $1,5 \mathrm{~mL}$ de solvente: $0,3 \mathrm{~mL}$ de clorofórmio, $48 \mathrm{~mL}$ de metanol, $47 \mathrm{ml}$ de $\mathrm{H}_{2} \mathrm{O}$ deionizada; após a terceira lavagem, foram pipetados $200 \mu \mathrm{L}$ para tubo cônico e evaporados em banho-maria a $60^{\circ} \mathrm{C}$; a parede do tubo foi lavada duas vezes, com 2,0 $\mathrm{mL}$ de clorofórmio. Foi evaporada após cada adição de clorofórmio, e o tubo seco foi colocado em banho de gelo e acrescentadas três gotas de acetona gelada. Deixado em repouso por $5 \mathrm{mi}$ nutos; acrescentado $0,75 \mathrm{~mL}$ de acetona gelada, deixado em repouso por 15 minutos, centrifugado por 10 minutos a $2500 \mathrm{rpm}$, desprezado o sobrenadante por inversão do tubo; o precipitado foi resuspenso em $10 \mu \mathrm{L}$ de clorofórmio e foram aplicados $5 \mu \mathrm{L}$ de amostras e padrões em placa de sílica-gel 60 , ativada em estufa a $110^{\circ} \mathrm{C}$.

O solvente utilizado para a corrida cromatográfica foi composto de $12,8 \mathrm{~mL}$ clorofórmio, 4,0 mL de metanol, 1,92 $\mathrm{mL}$ de ácido acético glacial e $0,32 \mathrm{~mL}$ de água deionizada. Após a corrida, a placa foi corada com mistura de $325 \mathrm{mg}$ de ácido fosfomolíbdico e $5 \mathrm{ml}$ de metanol. As leituras das amostras e dos padrões foram feitas em densitômetro marca Procyon. As placas para cromatografia eram de sílica-gel 60 , sem indicador de fluorescência, marca Merck. Os padrões, da marca Sigma, foram lecitina-esfingomielina $1: 1$, em clorofórmio-metanol, na concentração de $1 \mu \mathrm{g} / \mathrm{mL}$; fosfatidil-glicerol $2 \mu \mathrm{g} /$ $\mathrm{mL}$, em clorofórmio-metanol, e fosfatidil-inositol $2 \mu \mathrm{g} / \mathrm{mL}$, em clorofórmio.

A proporção dentro das classes de recémnascidos (PIG, AIP e GIG) foi avaliada pelo teste do $\chi^{2}$. Para as variáveis glicemia, peso corpóreo, peso e dosagem de fosfolipídios (L, E, PG e PI) dos pulmões dos recém-nascidos utilizou-se a análise de variância para fatorial inteiramente aleatória, sorteando-se seis ratas por grupo. Para a glicemia materna, medida ao longo do tempo, foi utilizada análise de perfil e, para correlação entre 
as variáveis, a análise de correlação, adotando-se $5 \%$ como limite de significância $(\mathrm{p}<0,05)^{13,14}$.

Este trabalho foi aprovado pelo Comitê de Ética em Experimentação Animal da Faculdade de Medicina de Botucatu.

\section{Resultados}

As médias glicêmicas maternas foram normais no grupo controle $(110 \mathrm{mg} / \mathrm{dL})$ e elevadas nos grupos diabéticos $(150 \mathrm{mg} / \mathrm{dL}$ no DM e 260 $\mathrm{mg} / \mathrm{dL}$ no DG), e refletiram-se sobre os filhotes, que apresentaram normoglicemia nos grupos controle $(94 \mathrm{mg} / \mathrm{dL})$ e diabete moderado (DM $120 \mathrm{mg} / \mathrm{dl}$ ) e hiperglicemia no diabete grave (DG - $208 \mathrm{mg} / \mathrm{dL}$ ) (Figura 1).

Os filhotes de ratas com DM tiveram maior peso $(5,2 \mathrm{~g})$ e elevada proporção de recém-nascidos GIG $(19,4 \%)$. Os filhotes de ratas com DG tiveram menor peso $(4,7 \mathrm{~g})$ e predomínio de PIG $(73,0 \%)$ (Tabela 1$)$.

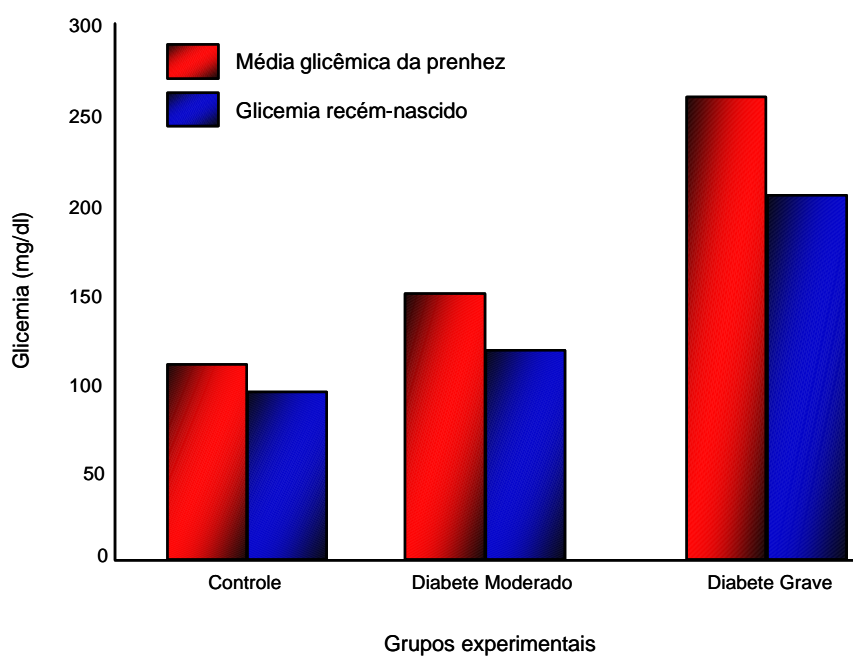

Estatística:

Média glicêmica da prenhez: $D G>D M>C$. Teste $F=101,49$; valor crítico $=3,52 ; p<0,001$. Glicemia de filhotes: $D G>(C=D M)$ Glicemia do recém-nascido. Teste $F=47,63 ; p<0,001$.

Figura 1 - Média glicêmica da prenhez e glicemia do "pool" de recém-nascidos de ratas nos três grupos experimentais

Tabela 1 - Média e desvio-padrão dos pesos corporal e pulmonar e classificação dos recém-nascidos (RN) em PIG, AIP e GIG nos três grupos experimentais

\begin{tabular}{|c|c|c|c|c|c|}
\hline \multirow[b]{2}{*}{ Grupos } & \multicolumn{2}{|c|}{ Peso $(g)^{(*)}$} & \multicolumn{3}{|c|}{ Classificação RN $(\%)^{(*)}$} \\
\hline & Corporal & Pulmonar & PIG & AIP & GIG \\
\hline Controle & $5,1 \pm 0,2 a b$ & $0,155 \pm 0,011 a_{1}$ & $26,8 \mathrm{a}_{2}$ & $61,4 a_{3}$ & $11,7 a_{4}$ \\
\hline Diabete moderado & $5,2 \pm 0,4 \mathrm{a}$ & $0,159 \pm 0,012 a_{1}$ & $22,9 \mathrm{a}_{2}$ & $57,6 a_{3}$ & $19,4 \mathrm{a}_{4}$ \\
\hline Diabete grave & $4,7 \pm 0,2 b$ & $0,145 \pm 0,010 a_{1}$ & $73,0 \mathrm{~b}_{2}$ & $20,9 b_{3}$ & $6,1 b_{4}$ \\
\hline Estatística & $F=3,63$ & $F=1,926$ & $\chi^{2}=115,5$ & $\chi^{2}=75,2$ & $\chi^{2}=8,4$ \\
\hline Valor $p$ & $p<0,05$ & $p>0,05$ & $p<0,05$ & $p<0,05$ & $p<0,05$ \\
\hline
\end{tabular}

$\left.{ }^{*}\right)$ médias seguidas de mesma letra e índice não diferem entre si ao nível de $5 \%$ de probabilidade

Estatística: valor crítico de $r(0,01)=0,35$; valor observado $=0,70 \backslash$ a correlação é significativa

O peso pulmonar dos filhotes foi semelhante nos três grupos $(0,155 \mathrm{~g}$ no controle; $0,159 \mathrm{~g}$ no DM e 0,145 g no DG), mas houve correlação significativa entre os pesos corporal e pulmonar em $70 \%$ dos casos $(r=0,7)$ (Tabela 1$)$.

A composição fosfolipídica do pulmão foi semelhante entre os grupos controle e diabéticos nas concentrações de L $(5,20 \mu \mathrm{g} / \mathrm{mL}$ no controle, $5,90 \mu \mathrm{g} / \mathrm{mL}$ no DM e 5,10 $\mu \mathrm{g} / \mathrm{mL}$ no DG), E $(2,80 \mu \mathrm{g} / \mathrm{mL}$ no controle, $3,20 \mu \mathrm{g} / \mathrm{mL}$ no $\mathrm{DM}$ e $1,80 \mu \mathrm{g} / \mathrm{mL}$ no $\mathrm{DG})$ e na relação $\mathrm{L} / \mathrm{E}(2,10$ no controle, 1,90 no DM e 1,60 no DG); a correlação entre lecitina e esfingomielina foi significativa em $97 \%$ dos casos ( $\mathrm{r}=0,97$ ) (Figura 2). Os filhotes do grupo com DM apresentaram concentração menor de PG $(2,95 \mu \mathrm{g} / \mathrm{mL})$ e PI $(3,55 \mu \mathrm{g} / \mathrm{mL})$ que os filhotes do grupo controle $(6,90 \mu \mathrm{g} / \mathrm{mL}$ de PG e $6,80 \mu \mathrm{g} / \mathrm{mL}$ de PI) e, no grupo com DG $(5,0 \mu \mathrm{g} /$ $\mathrm{mL}$ de PG e $2,95 \mu \mathrm{g} / \mathrm{mL}$ de PI), esta concentração não se diferenciou dos demais. A relação PG/ PI foi semelhante entre os grupos $(2,10$ no controle, 1,0 no DM e 2,10 no DG), e a correlação entre PG e PI foi significativa em $52 \%$ dos casos (Figura 3).

\section{Discussão}

No esquema fisiopatológico proposto por $\mathrm{Oh}^{15}$, todas as repercussões sobre os conceptos de mães diabéticas decorrem da hiperglicemia materna. Existe consenso na literatura sobre a relação entre peso do recém-nascido de ratas dia- 
béticas e intensidade da hiperglicemia mater$n a^{1,16}$. Entretanto, esta relação não é direta, sendo o diabete moderado considerado modelo de macrossomia fetal e o diabete grave de retardo de crescimento intra-uterino ${ }^{1,15}$, dados confirmados neste trabalho.

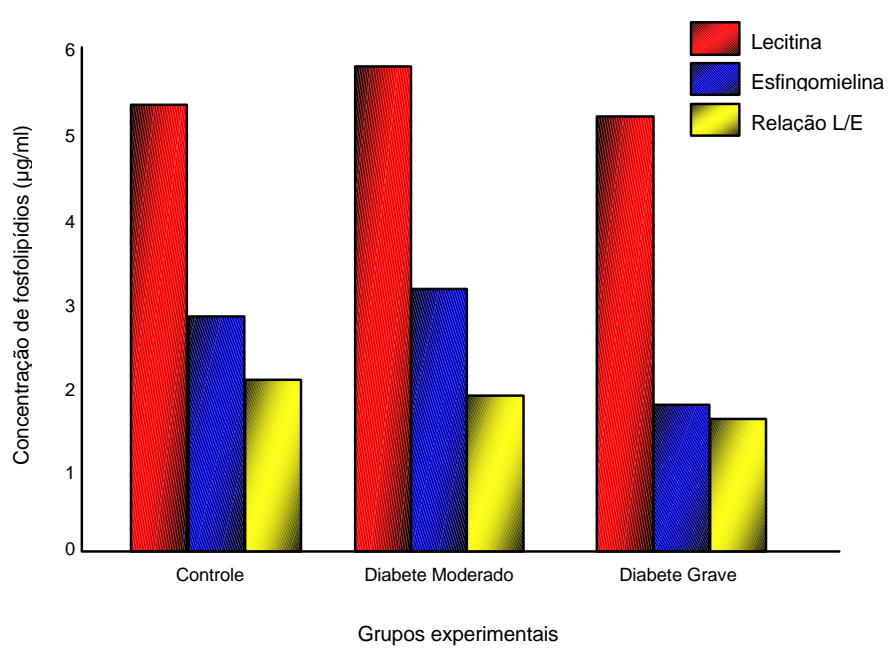

Estatística:

Concentração de lecitina: $C=D M=D G$. Teste $F=0,457$; valor crítico $=3,17 \quad p>0,05$ Concentração de esfingomielina: $C=D M=D G$. Teste $F=0,231$; valor crítico $=3,17 p>0,05$ Relação L/E: $C=D M=D G$. Teste $F=0,874 ; p>0,10$. Valor crítico de $r(0,01)=0,35$. Valor observado $=0,97 \therefore$ a correlação é significativa.

Figura 2 - $\quad$ Média da concentração de lecitina, esfingomielina e a relação L/E, nos três grupos experimentais

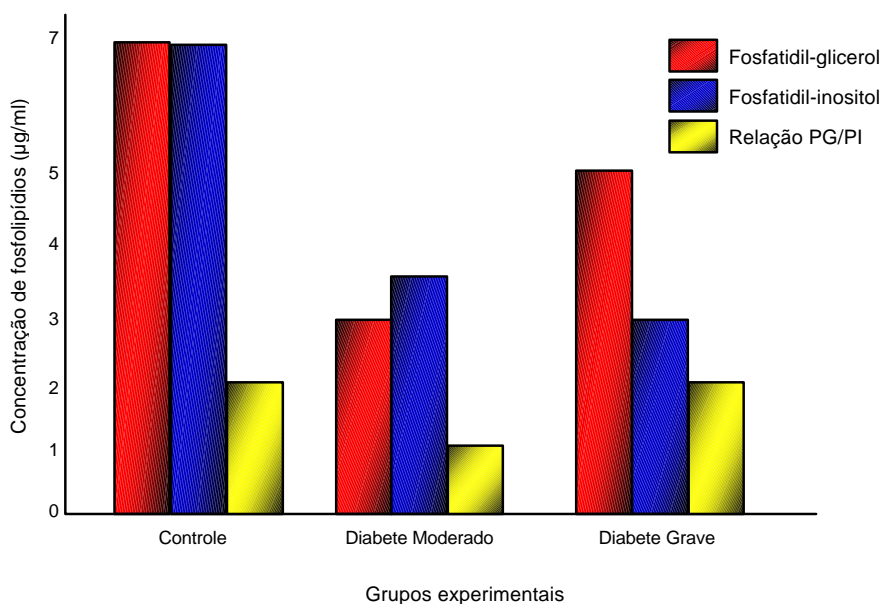

Estatística:

Concentração de fosfatidil-glicerol: $D M<C$; $D G$ é intermediário. Teste $F=6,232$; valor crítico $=3,17 p<0,01$.

Concentração de fosfatidil-inositol: $D M=D G<C$. Teste $F=6,159$; valor crítico $=3,17 p<0,01$. Relação PG/PI: $C=D M=D G$. Teste $F=1,306$; valor crítico $=3,17 p>0,10$. Valor crítico de $r(0,01)=0,35$. Valor observado $=0,52 \therefore$ a correlação é significativa.

Figura 3 - Média das concentrações de fosfatidil-glicerol (PG) e fosfatidilinositol (PI) e a relação PG/PI, nos três grupos experimentais

O peso pulmonar dos filhotes foi semelhante entre os três grupos, porém a correlação entre os pesos corporal e pulmonar fetal foi significativa em $70 \%$ dos casos, mostrando que os maiores pulmões foram encontrados entre os filhotes de ratas com diabete moderado.

A composição dos fosfolipídios, semelhante nos pulmões de recém-nascidos a termo de ratas dos grupos controle, diabete moderado e diabete grave, confirma resultados de trabalhos clínicos anteriores, demonstrando que a determinação da relação L/E não é bom parâmetro para analisar a maturidade pulmonar de filhos de mães diabéticas ${ }^{2,17}$.

Hallman e Teramo ${ }^{18}$ salientam que a presença de $\mathrm{PG}$ associado com relação $\mathrm{L} / \mathrm{E} \geq 2,0$ identifica o pulmão fetal maduro. Os nossos resultados demonstram que os filhotes de ratas com diabete moderado têm relação $\mathrm{L} / \mathrm{E}>2$ e menor dosagem de PG e PI que o grupo controle. Como esses filhotes têm maior peso corpóreo e, em $70 \%$ dos casos $(r=0,7)$ maior peso pulmonar, deveria ser esperada também maior concentração de PG e PI nos seus pulmões, porém isto não ocorreu. A maior concentração de insulina no meio interno dos fetos de ratas com diabete moderado deve ter sido o fator etiológico para explicar o aumento do peso pulmonar e a diminuição dos fosfolipídios, confirmando o trabalho experimental de Smith et al. ${ }^{5}$. Os fetos de ratas com diabete moderado têm ilhotas pancreáticas aumentadas de tamanho e com maior produção de insulina, confirmada por técnica de imunohistoquímica ${ }^{16}$. A análise conjunta da atividade pancreática fetal com o perfil fosfolipídico pulmonar evidencia que nos animais com diabete moderado, a hiperinsulinemia fetal deve ser o fator responsável pelo atraso na produção do surfactante pulmonar. Os resultados obtidos neste trabalho permitem a compreensão dos achados clínicos de Gluck e Kulovich ${ }^{12}$ de que os recém-nascidos de mães diabéticas das classes A, B e C de White ${ }^{4}$ têm atraso na maturidade pulmonar. A associação dos achados clínicos de maior incidência de SDR nos recém-nascidos de mães diabéticas ${ }^{17,19} \mathrm{com}$ os resultados deste experimento sugere que pulmões grandes e com baixa concentração de PG e PI sejam a causa da maior incidência desta patologia nesse grupo de recém-nascidos. Os animais com diabete moderado simulam o diabete gestacional humano e o diabete clínico de curta duração, que se associam à macrossomia fetal, à menor produção de surfactante pulmonar e à maior incidência de SDR.

Os recém-nascidos das ratas com diabete grave, que em sua maioria são PIG, têm a mesma dosagem de PG e PI que o grupo controle. 
Esses recém-nascidos apresentam menor peso pulmonar em $70 \%$ dos casos e a mesma concentração de PG e PI que o grupo controle, ou seja, têm na realidade aceleração da maturidade pulmonar. Isto mostra que o diabete grave é fator estimulante do processo de amadurecimento pulmonar. A causa desse amadurecimento pulmonar acelerado deve ser a hipoinsulinemia fetal, pois os pâncreas dos fetos com diabete grave têm ilhotas aumentadas de tamanho mas não têm células insulino-positivas, evidenciando falência funcional do pâncreas ${ }^{15}$. Os resultados deste trabalho corroboram a afirmação de Tyrala ${ }^{19}$ de que as diabéticas das classes $\mathrm{F}$ e $\mathrm{R}$ de White ${ }^{4}$ têm aceleração da maturidade pulmonar fetal e menor incidência de SDR.

A insulina, em maior ou menor quantidade, deve modular a produção de surfactante pulmonar e explicar as disparidades de que uma mesma patologia materna possa atrasar e acelerar a maturidade pulmonar fetal. A relação PG/ PI não mostrou diferença entre os três grupos, apesar do menor valor no grupo diabete moderado. O cálculo da relação $\mathrm{PG} / \mathrm{PI}$, usando as médias de cada grupo, demonstra que no controle esta relação é de 1,0 , no grupo diabete moderado ela é menor que 1,0 e no diabete grave é maior que 1,0. Estes achados estão em consonância com os dados de exame do líquido amniótico de fetos de mulheres diabéticas, com e sem maturidade pulmonar ${ }^{20}$. Em vista dos resultados deste trabalho e dos conhecimentos da literatura, a explicação fisiopatológica para os desvios opostos no amadurecimento pulmonar entre os filhos de ratas com diabete moderado e grave deve estar relacionada com a insulinemia fetal.

Este trabalho experimental confirma os conhecimentos clínicos, explicando os resultados conflitantes da maturidade pulmonar em diabéticas, encontrados em vários trabalhos clínicos $\mathrm{e}$ experimentais da literatura. Ratifica, ainda, a necessidade de realização do perfil fosfolipídico pulmonar no líquido amniótico de gestantes diabéticas, visto que o amadurecimento pulmonar é dependente da função pancreática fetal, inacessivel à avaliação clínica.

Assim concluimos que o retardo do amadurecimento pulmonar dos recém-nascidos de ratas com diabete moderado é explicado pelo maior peso pulmonar associado à menor concentração de PG e PI; a aceleração do amadurecimento pulmonar dos recém-nascidos de ratas com diabete grave é explicada pelo menor peso pulmonar associado à mesma concentração de PG e PI.

\section{SUMMARY}

Purpose: to evaluate the effects of maternal diabetes on the fetal lung phospholipid profiles of rats with moderate and severe diabetes measuring lecithin (L), sphingomyelin $(S)$, phosphatidyl-glycerol (PG), phosphatidyl-inositol (PI), and the relationships between $L / S$ and PG/PI.

Methods: fifty-four mature Wistar rats were submitted to experimental diabetes and pregnancy ${ }^{l}$. Diabetes was induced by alloxan (42 $\mathrm{mg} / \mathrm{kg}$ of weight, IV) and three groups were formed: control; moderate diabetes (MD), with glycemia levels between 120 and $200 \mathrm{mg} / \mathrm{dL}$, and severe diabetes (SD), with glycemia levels higher than $200 \mathrm{mg} / \mathrm{dL}$. On the 21st day, cesarian section was performed, and the fetal lungs were macerated and pooled. The phospholipids were measured by unidirectional thin-layer chromatography.

Results: 1) the fetal lungs of the rats with moderate diabetes showed higher weight $(0.159 \mathrm{~g})$ and lower concentration of $P G(3.0 \mu \mathrm{g} / \mathrm{mL})$ and $P I(3.4 \mu \mathrm{g} / \mathrm{mL})$ than the controls, and the same relationship between $L / S$ (2.2) and PG/PI (2.0). The fetal lungs of the rats with severe diabetes showed lower weight $(0.145 \mathrm{~g})$, the same values of $L / S$ (1.9) and PG/PI (2.1), and lower PI $(5.1 \mu \mathrm{g} / \mathrm{mL})$ value than the controls.

Conclusions: 1) the pulmonary maturity retardation in the pups of rats with moderate diabetes is explained by the higher pulmonary weight associated with lower concentration of $P G$ and $P I ; 2)$ the pulmonary maturity acceleration in the pups of rats with severe diabetes is explained by the lower pulmonary weight associated with the same concentration of $P G$ and $P I$.

KEY WORDS: Diabetes. Lung maturity. Fetal lung phospholipid profile.

\section{Referências}

1. Calderon IMP, Rudge MVC, Brasil MAM, Henry MACA. Diabete e gravidez experimental em ratas. I - Indução do diabete, obtenção e evolução da prenhez. Acta Cir Bras 1991; 7:142-6.

2. Kulovich MV, Hallman MB, Gluck L. The lung profile. I. Normal pregnancy. Am J Obstet Gynecol 1979; 135:57-63.

3. Pignol B, Bourlon J, Rieutort M. Diminution du phosphatidilglycerol pulmonaire chez les foetus de rattes rendus diabétiques par la streptozotocine. C R Séances Acad Sci III 1983; 297:339-42.

4. White P. Symposium on diabetes mellitus. Pregnancy complicating diabetes. Am J Med 1949; 7:60916. 
5. Smith BT, Giroud CJP, Robert M, Avery ME. Insulin antagonism of cortisol action on lecithin synthesis by cultured fetal lung cells. J Pediatr 1975; 87:953-5.

6. Mason RJ, Dobbs LG, Greenleaf RD, Williams MC. Alveolar type II cells. Fed Proc 1977; 36:2697702.

7. Mueller-Heubach E, Caritis SN, Edelstone DI, Turner JH. Lecithin/sphingomyelin ratio in amniotic fluid and its value for the prediction of neonatal respiratory distress syndrome in pregnant diabetic women. Am J Obstet Gynecol 1978; 130: 28-34.

8. Guttenlag SH, Ballard RA. Fetal lung development. In: Reece EA, Constan DR, editors. Diabetes mellitus in pregnancy. $2^{\text {nd }}$ ed. New York: Churchill-Livingstone; 1995. p.93-106.

9. Epstein MF, Farrell PM, Chez RA. Fetal lung lecithin metabolism in the glucose - intolerant rhesus monkey pregnancy. Pediatrics 1976; 57:722-8.

10.Sosenko IR, Lawson EE, Demottaz V, Frantz ID $3^{\text {rd }}$. Functional delay in lung maturation in fetuses of diabetic rabbits. J Appl Physiol 1980; 48:6437 .

11.Pinter E, Peyman JA, Snow K, Jamieson JD, Warshaw JB. Effects of maternal diabetes on fetal rat lung ion transport. Contribution of alveolar and bronchiolar epithelial cells to $\mathrm{Na}^{+}$, $\mathrm{K}^{+}$, ATPase expression. J Clin Invest 1991; 87:821-30.
12. Gluck L, Kulovich MV. Lecithin/sphingomyelin ratio in amniotic fluid in normal and abnormal pregnancy. Am J Obstet Gynecol 1973; 115:53946.

13. Morrison DF. Multivariate statistical methods. $1^{\text {st }}$ ed. New York: McGraw-Hill; 1967. p.338.

14.Zar JH. Biostatistical analysis. $2^{\text {nd }}$ ed. Englewood Cliffs: Prentice- Hall; 1984. p.718.

15.Oh W. Neonatal care and long-term outcome on infants of diabetic mothers. In: Merkatz IR, Adam PAJ, editors. The Diabetic Pregnancy: a perinatal perspective. New York: Grune \& Stratton; 1979. p.267.

16. Calderon IMP. Influência do binômio diabete e gravidez na atividade endócrina do pâncreas materno e fetal [tese]. Botucatu: Faculdade de Medicina de Botucatu; 1994.

17.Kjos SL, Walther FJ, Montoro M, Paul RH, Diaz F, Stabler M. Prevalence and etiology of respiratory distress in infants of diabetic mothers: predictive value of fetal lung maturation tests. Am J Obstet Gynecol 1990; 163:898-903.

18.Hallman M, Teramo K. Amniotic fluid phospholipid profile as a predictor of fetal maturity in diabetic pregnancies. Obstet Gynecol 1979; 54:703-7.

19.Tyrala EE. The infant of the diabetic mother. Obstet Gynecol Clin North Am 1996; 23:221-41.

20.Rudge MVC, Calderon IMP, Ramos MD, Peraçoli JC, Souza LMS, Bossolan G. Perfil fosfolipídico do líquido amniótico de gestantes diabéticas. Rev Bras Ginecol Obstet 1996; 18:785-98.

\title{
AVISO
}

\section{COMUNICAMOSONOVOENDERECOODA} SECRETARIAEXEOUIVADAFEBRASGO

\author{
Av. das Américas, 8445 sala 711 - Barra da Tijuca \\ Rio de Janeiro-RJ-CEP22793-081 \\ e-mail:publicacoes@ffebrasgo.org.br \\ febrasgo@domain.com.br \\ secretaria_executiva@febrasgo.org.br \\ Home Page: http://www.febrasgo.org:br \\ Tel: (21) 487-6336 Fax: (21) 429-5133
}

